\title{
High prevalence of advanced colorectal neoplasia in the Thai population: a prospective screening colonoscopy of 1,404 cases
}

Bunchorn Siripongpreeda ${ }^{1 *}$, Chulabhorn Mahidol ${ }^{1,2,3}$, Navara Dusitanond1', Tassanee Sriprayoon ${ }^{1}$, Bunlung Muyphuag ${ }^{1}$, Thaniya Sricharunrat', Narongchai Teerayatanakul', Watanya Chaiwong ${ }^{1}$, Wipra Worasawate', Prassanee Sattayarungsee ${ }^{1}$, Juthamas Sangthongdee ${ }^{1}$, Jirapa Prarom', Gaidganok Sornsamdang ${ }^{1}$, Kamonwan Soonklang ${ }^{1}$, Kasiruck Wittayasak ${ }^{1}$ and Chirayu U. Auewarakul ${ }^{1,3}$

\begin{abstract}
Background: Increasing morbidity and mortality from colorectal cancer is evident in recent years in the developing Asian nations. Particularly in Thailand and most neighbouring low-income countries, screening colonoscopy is not yet recommended nor implemented at the national policy level.
\end{abstract}

Methods: Screening colonoscopy was offered to 1,500 healthy volunteers aged 50-65 years old who were registered into the program between July 2009 and June 2010. Biopsy and surgery was performed depending on the identified lesions. Fecal immunochemical tests (FIT) were additionally performed for comparison with colonoscopy.

Results: There were 1,404 participants who underwent colonoscopy. The mean age of the cohort was $56.9 \pm 4.2$ years and $69.4 \%$ were females. About $30 \%$ (411 cases) of all colonoscopies had abnormal colonoscopic findings, and of these, 256 cases had adenomatous polyps. High risk adenomas (villous or tubulovillous or high grade dysplasia or size $>1 \mathrm{~cm}$ or $>3$ adenomatous polyps) were found in 98 cases (7\%), low risk adenoma in 158 cases (11.3\%), and hyperplastic polyps in 119 cases (8.5\%). Eighteen cases (1.3\%) had colorectal cancer and $90 \%$ of them (16 cases) were non-metastatic including five stage 0 cases, seven stage I cases, and four stage IIA cases. Only two cases had metastasis: one to regional lymph nodes (stage IIIB) and another to other organs (stage IVA). The most common cancer site was the distal intestine including rectum (7 cases, $38.9 \%$ ) and sigmoid colon (7 cases, $38.9 \%$ ). Ten colorectal cancer cases had positive FIT whereas 8 colorectal cancer cases were FIT-negative. The sensitivity and specificity of FIT was $55.6 \%$ and $96.2 \%$, respectively, while the positive predictive value was $16.4 \%$ and negative predictive value was $99.4 \%$. The overall survival of colorectal cancer cases at 5 -year was $83.3 \%$.

Conclusion: High prevalence of colorectal cancer and high-risk adenoma was found in the Thai population aged 50-65 years old by screening colonoscopy. FIT was not sensitive enough to detect colorectal cancer in this asymptomatic cohort. Integration of screening colonoscopy into the national cancer screening program should be implemented to detect early cases of advanced colorectal neoplasia and improve survival of colorectal cancer patients in Thailand.

Keywords: Colorectal cancer, Adenoma, Advanced colorectal neoplasia, Screening colonoscopy, Fecal immunochemical test, National policy

(Continued on next page)

\footnotetext{
* Correspondence: bunchorn_sir@yahoo.com

'Chulabhorn Hospital, Bangkok, Thailand

Full list of author information is available at the end of the article
} 
(Continued from previous page)

Abbreviations: BMI, Body mass index; CT colonography, Comperized tomographic colonography; FIT, Fecal immunochemical tests; FOB, Fecal occult blood; NCCN, National Comprehensive Cancer Network; NPV, Negative predictive value; PPV, Positive predictive value; UICC, The Union for International Cancer Control

\section{Background}

Colorectal cancer is one of the most common causes of cancer death globally each year, along with lung, liver, prostate, and breast cancer [1]. Disease incidence of economically developed countries in Asia such as Japan, Korea and Singapore abruptly approached the level of the Western countries. Data from the National Cancer Institute of Thailand Cancer Registry also showed a gradual increase in the number of new colorectal cancer patients in recent years with increased advance stage cases identified [2]. Colorectal cancer screening can diagnose cases in early stages, decrease cancer mortality and potentially prevent this disease [3, 4]. Detection and proper management of advanced colorectal neoplasia which included malignant and some high risk colorectal lesions that need therapeutic interventions should prevent progression and worse outcomes in the affected cases.

Colonoscopy is one of the cancer screening tests that achieves goals of premalignant and early stage cancer detection and when it is coupled with polypectomy, it can prevent and reduce the incidence of disease, and finally of all results, decrease mortality from colorectal cancer [3-5]. Therefore, colonoscopy is recommended in colorectal cancer screening guideline since 1997 [6]. However, screening colonoscopy is presently not included in the national colorectal cancer screening policy in Thailand nor widely recommended for the Thai population. Most previous studies utilized fecal immunochemical test (FIT) as a first screening tool although the majority of the Thai population do not undergo such testing on a regular basis [7-9]. This study aimed to provide essential information on consideration of implementation of a nation-wide colorectal cancer screening program in Thailand and developing countries. Screening colonoscopy was performed as a first screening tool in all cases while FIT was done as a comparison.

\section{Methods}

\section{Study participants}

After the study protocol had been approved by the Human Research Ethical Committee of Chulabhorn Research Institute, we enrolled participants between 50 and 65 years of age with no past medical history of colorectal cancer or poorly controlled underlying diseases in July 2009. In total, 1,612 applicants expressed their willingness to participate in this project. All participants were educated about colorectal cancer and screening methods that were to be used in this study as well as study objectives, details of each procedure including possible complications, and usage of data from the study. Some patients were excluded based on age, poor medical problem control, or the inability to be followed over a long-term period. Finally, 1,404 participants underwent colonoscopy between July 2009 and June 2010 after they provided informed consent. Their demographic data, medical history, physical examination, and pre-operative management were collected.

\section{Screening colonoscopy and pathological diagnosis}

Bowel preparation before colonoscopy was established by using $90 \mathrm{~mL}$ of sodium phosphate after a low fiber diet for 2 days. All participants underwent colonoscopy under intravenous anaesthesia. The colonoscopic findings in each colonic section were recorded. If abnormal mucosal findings or polyps were found, the removed tissue was sent for pathological diagnosis. We categorized abnormal tissue from colonoscopic findings and pathological reports into malignant, high-risk adenoma, low risk adenoma, and non-adenomatous polyps, for which each group underwent different appropriate management according to National Comprehensive Cancer Network (NCCN) guidelines for colorectal cancer screening. High-risk adenoma cases recommended to have repeat colonoscopy earlier than low risk adenoma cases included one of the following colonoscopic and pathological criteria: size $\geq 1 \mathrm{~cm}, \geq 3$ adenomas, or tubulovillous or villous adenoma or high grade dysplasia. All malignant cases were diagnosed by pathological staging using the Seventh edition of the Union for International Cancer Control (UICC) TNM Classification of Malignant Tumours [10]. Patients with colorectal cancer were treated according to the NCCN Guidelines [11]. Participants without malignancy were seen annually in the clinic for general evaluation, and FIT and follow-up colonoscopy was to be performed based on clinical findings and colorectal cancer risks. The second screening colonoscopy was respectively performed at 3, 4, and 5 years follow-up for high risk adenoma cases, low risk adenoma/hyperplastic polyp cases, and normal colonoscopy cases.

\section{Screening fecal immunochemical test (FIT)}

FIT was performed in parallel to screening colonoscopy by fecal occult blood (FOB) one-step test device, a rapid chromatographic immunoassay (Abon Biopharm Hangzhou, China) with relative sensitivity of $93.6 \%$ and relative specificity of $99.1 \%[12,13]$. The FOB one-step test can detect fecal blood as low as $50 \mathrm{ng} / \mathrm{mL}$ or $6 \mu \mathrm{g} / \mathrm{g}$ feces and is 
specific for human hemoglobin at a concentration of $1.0 \mathrm{mg} / \mathrm{mL}$. Fecal specimens were self-collected from the first bowel movement in the morning of the appointed date for FIT test which occurred before the start of bowel preparation for screening colonoscopy. The specimens were stored in a clean and dry container and brought in to the hospital by the participants at environmental temperature. The participants were instructed to hand in the samples to the laboratory within $6 \mathrm{~h}$ of collection.

\section{Statistical analysis}

Statistical analyses were performed with STATA version 12.1. Data of the participants were reported as means and standard deviation for continuous variables and as proportions and absolute counts for categorical variables. We also estimated FIT sensitivity, specificity and predictive values in detecting colorectal cancer.

\section{Results}

\section{Demographic characteristics of the study cohort}

Of the 1,404 participants, there were 429 males and 975 females, with a mean age of $56.9 \pm 4.2$ years. Most $(81.8 \%)$ of the participants lived in Bangkok Metropolitan and connective territorial provinces during the time of the colonoscopy. Overall, $96.1 \%$ of participants had no lower gastrointestinal symptoms, i.e. bowel habit changes or lower gastrointestinal bleeding or decreased stool calibre or anemia, and the majority $(91.7 \%)$ did not have a family history of colorectal cancer, respectively (Table 1). Complete colonoscopy was accomplished in $99.6 \%(1,399)$ of cases. In five incomplete colonoscopy cases, patients were further investigated by $\mathrm{CT}$ colonography, all of which produced normal findings.

\section{Screening colonoscopy findings}

About $30 \%$ (411 cases) of all colonoscopies had abnormal colonoscopic findings. Malignancy was found in $1.3 \%$ (18 cases) of all cases. Of all colonoscopies, $18.2 \%$ (256 cases) had adenomatous polyps, of which $7 \%$ (98 cases) were high risk adenoma. The other $9.8 \%$ (137 cases) had abnormal tissue, of which $8.5 \%$ (119 cases) were hyperplastic polyps (Fig. 1). The pathological diagnosis of malignant tissue in this study showed two cases of carcinoid tumor out of 18 cases. Others were adenocarcinoma with stages varying from stage 0 to stage 4 (Table 2). Nearly $90 \%$ (16 cases) were non-metastatic colorectal cancer; five stage 0 cases, seven stage I cases, and four stage IIA cases. Only two cases from our study had metastasis: one to regional lymph nodes (stage IIIB) and another to other organs (stage IVA). Most abnormalities that required tissue diagnosis were found in the left side of the colon (Fig. 2). The most common cancer site was rectum (7 cases, $38.9 \%$ ) and sigmoid colon (7 cases, $38.9 \%)$. Also, the most common site for high risk adenoma and low risk
Table 1 Demographic data of the study cohort $(N=1,404)$

\begin{tabular}{ll}
\hline Variable & $N(\%)$ \\
\hline Sex & \\
Male & $429(30.6)$ \\
Age & $975(69.4)$ \\
BMl & $56.9 \pm 4.2$ \\
$>25$ & \\
$\leq 25$ & $640(45.6)$ \\
Area & $764(54.4)$ \\
Bangkok and territories & \\
Other & $1148(81.8)$ \\
Lower gastrointestinal tract symptoms & $256(18.2)$ \\
Yes & \\
No & $55(3.9)$ \\
Family history of colorectal cancer & $1349(96.1)$ \\
Yes & \\
No & $117(8.3)$ \\
\hline
\end{tabular}

adenoma was sigmoid colon (30 \% and $35 \%$, respectively) and the second most common sites were ascending and transverse colon. Most adenoma had only low grade dysplasia. Only one case of high grade dysplasia was detected in a tubulovillous adenoma case. The gender proportion in 256 cases of adenoma group was 117 males (45.7\%) and 139 females (54.3\%). For colorectal cancer cases, they were 8 males $(44.4 \%)$ and 10 females $(55.6 \%)$.

Table 3 summarizes histopathology findings of 55 cases with complaining symptoms that may have suggested cancer at the outset of screening and 117 cases with a family history of colorectal cancer. Among 55 cases, 3 developed colorectal cancer $(5.5 \%)$ as compared with 15 cases in asymptomatic cases $(1.1 \%)(p=0.031)$. Various types of adenomas and polyps were also found in symptomatic cases. If symptomatic cases were excluded, high risk adenoma and colorectal cancer accounted for $8.15 \%$ (110/1,349 cases). Four colorectal cancer cases developed in participants with a family history of colorectal cancer $(3.4 \%)$ whereas 14 colorectal cancer cases $(1.1 \%)$ were found in a no family history group $(p=0.056)$. Hyperplastic polyps tended to be more common in participants with a family history of colorectal cancer.

\section{Sensitivity and specificity of FIT in diagnosis of colorectal cancer}

As shown in Table 4, 10/18 colorectal cancer cases had positive FIT whereas 8 colorectal cancer cases were FITnegative. The sensitivity and specificity of FIT in detection of colorectal cancer was $55.6 \%$ and $96.2 \%$, respectively, while the positive predictive value (PPV) was $16.4 \%$ and 


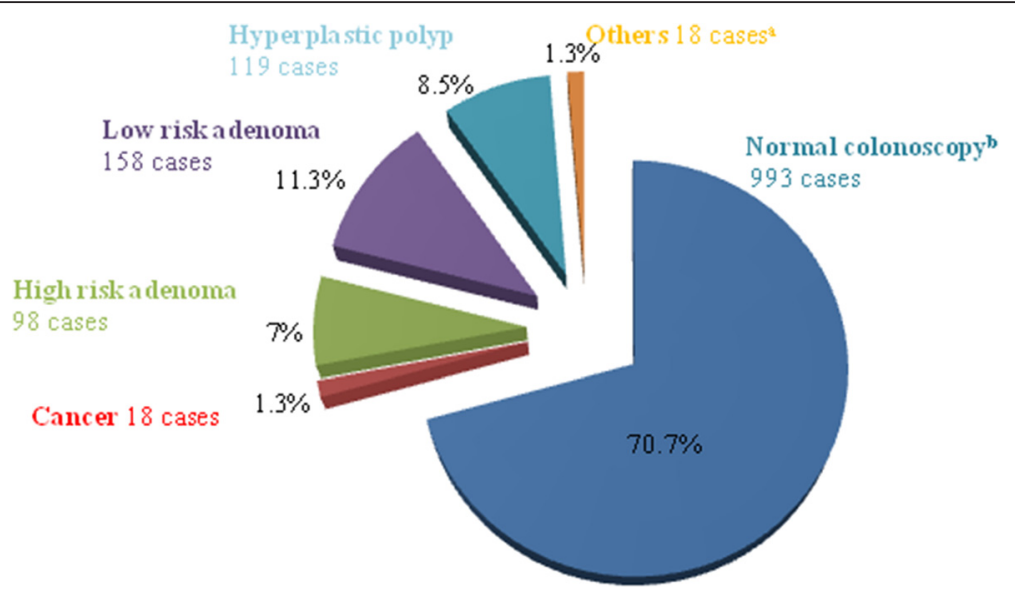

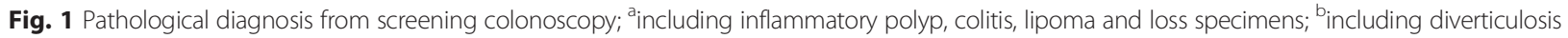
without biopsied tissues and hemorrhoids

the negative predictive value (NPV) was $99.4 \%$. Table 5 shows the distribution of FIT-positivity among participants with various histopathology findings. Most of adenoma cases were FIT-negative. FIT-positive non-cancer cases included6 high risk adenoma, 3 low risk adenoma, 8 hyperplastic polyps, and 33 cases with normal colonoscopy results.

\section{Follow-up of study participants and survival of colorectal cancer cases}

In the follow-up period after colonoscopic screening, there were three additional new cases of colorectal cancer. Two cases of intramucosal carcinoma of sigmoid colon and another case with stage 1 anal canal adenocarcinoma were found in the second year from the group previously identified as high risk adenoma, low risk adenoma and hyperplastic polyp, respectively. The mortality due to colorectal cancer cases in this study was 3/18 cases: 1 case with stage IV disease died in the first year, 1 case with stage IIA in the fourth year, and another case in stage

Table 2 Staging and 5-year survival rates of 18 colorectal cancer cases diagnosed by screening colonoscopy

\begin{tabular}{ll}
\hline Variable & $N(\%)$ \\
\hline Screening colonoscopy & $18(100)$ \\
Cancer & \\
Stage & $5(27.8)$ \\
0 & $7(38.9)$ \\
I & $4(22.2)$ \\
IIA & $1(5.6)$ \\
IIIB & $1(5.6)$ \\
IVA & $15(83.3)^{\mathrm{a}}$ \\
5-year survival rate &
\end{tabular}

${ }^{\mathrm{a}}$ One case died from unrelated hepatobiliarycancer
I died from unrelated primary hepatobiliary cancer. The overall survival of colorectal cancer cases at 5 year was $83.3 \%$ (88.9\% if excluded 1 death from unrelated cancer).

\section{Discussion}

The discovery rate of high risk adenoma and invasive colorectal cancer in this study $(8.15 \%)$ was nearly twice that of advanced colorectal neoplasia in the asymptomatic population $(4.5 \%)$ as reported from multiple studies in Asia but comparable to that of the symptomatic population $(7.8 \%)$ [14]. These patients should receive therapeutic intervention before progression to more advanced disease. When we excluded the amount criteria from the high risk adenoma group, the prevalence of advanced colorectal neoplasia in our study (3\%) and also adenocarcinoma (1.3\%) were still comparable to the country with a high incidence of colorectal cancer $[14,15]$. Prior hospital-based reports and retrospective

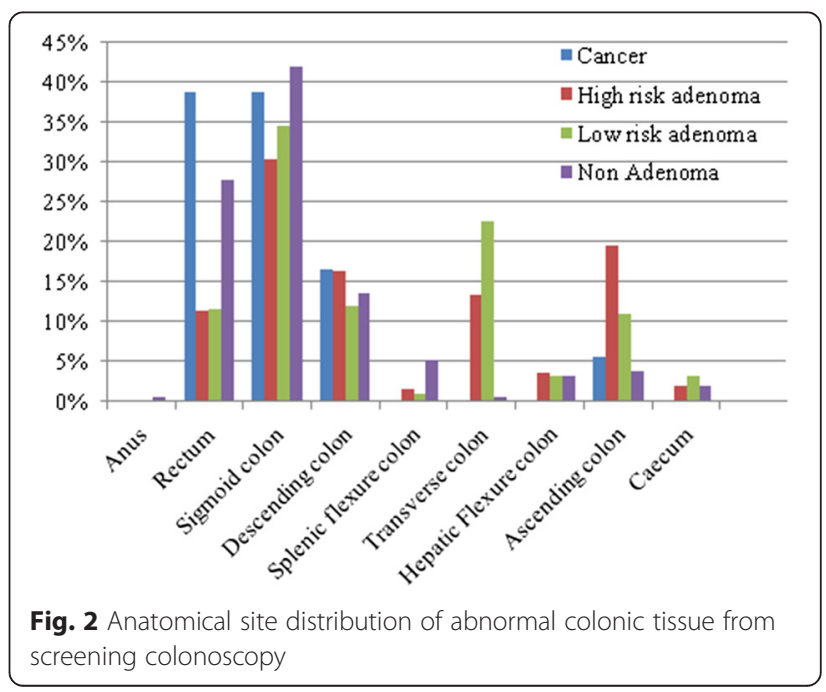


Table 3 Histological comparison between cases with or without symptoms at screening day 0 visit and between cases with or without family history of colorectal cancer

\begin{tabular}{|c|c|c|c|c|c|c|}
\hline & \multicolumn{3}{|c|}{ Symptoms that may suggest colorectal cancer at the outset } & \multicolumn{3}{|c|}{ Family history of colorectal cancer } \\
\hline & $\begin{array}{l}\text { Yes } \\
55 \text { cases }\end{array}$ & $\begin{array}{l}\text { No } \\
1,349 \text { cases }\end{array}$ & $P$-value & $\begin{array}{l}\text { Yes } \\
117 \text { cases }\end{array}$ & $\begin{array}{l}\text { No } \\
1,287 \text { cases }\end{array}$ & $P$-value \\
\hline \multicolumn{7}{|l|}{ Screening colonoscopy } \\
\hline Colorectal cancer & $3(5.5)$ & $15(1.1)$ & $0.031^{b}$ & $4(3.4)$ & $14(1.1)$ & $0.056^{\mathrm{b}}$ \\
\hline \multicolumn{7}{|l|}{ Stage } \\
\hline 0 & 1 & 4 & & 2 & 3 & \\
\hline । & 0 & 6 & & 0 & 6 & \\
\hline$\| \mathrm{A}$ & 1 & 4 & & 1 & 4 & \\
\hline$\| I B$ & 0 & 1 & & 1 & 0 & \\
\hline IVA & 1 & 0 & & 0 & 1 & \\
\hline High risk adenoma & $3(5.5)$ & $95(7.0)$ & & $0(0.0)$ & $98(7.6)$ & \\
\hline Low risk adenoma & $10(18.2)$ & $148(11.0)$ & & $13(11.1)$ & $145(11.3)$ & \\
\hline Hyperplastic polyp & $3(5.5)$ & $116(8.6)$ & & $14(12.0)$ & $105(8.2)$ & \\
\hline Other pathological diagnosis ${ }^{a}$ & $0(0.0)$ & $18(1.3)$ & & $2(1.7)$ & $16(1.2)$ & \\
\hline No colorectal tumor & $36(65.5)$ & 957 (70.9) & & $84(71.8)$ & 909 (70.6) & \\
\hline
\end{tabular}

${ }^{a}$ Inflammatory polyp, colitis, and lipoma

${ }^{\mathrm{b}}$ Fisher Exact Test

studies from Thailand also showedcancer detection rate by colonoscopy of $0.6-7.1 \%$ in different studied population $[7-9,16,17]$. These previous studies utilized FIT as a first screening tool and were unlike our study whereby colonoscopy was performed as a first screening tool.

The abnormal colonic tissue $(29.3 \%)$ findings from our screening colonoscopy study are in the range of polyp detection rates $(25-37 \%)$ reported in other studies from within and outside Thailand [16-20]. Both adenomatous polyp and hyperplastic polyposis can accumulate worse genetic changes and become malignant [21, 22]. Therefore, colorectal cancer screening would benefit this population. Although most abnormalities that required tissue diagnosis were found in the left side of the colon, complete colonoscopy should be done to include low and high risk adenomas in the second most common locations, the transverse and ascending colon.

There are some key differences in the selection of subjects for our study compared with others: our study included screening criteria for an age group at high risk of colorectal cancer [23], while others included data

Table 4 Diagnostic value of FIT in the diagnosis of colorectal cancer

\begin{tabular}{lll}
\hline FIT & Colonoscopy & \\
\cline { 2 - 3 } & Malignancy & No malignancy $^{\mathrm{a}}$ \\
\hline Positive & 10 & 51 \\
Negative & 8 & 1,295 \\
Total & 18 & 1,346 \\
\hline
\end{tabular}

${ }^{\mathrm{a}} \mathrm{FIT}$ not done in 40 cases

Sensitivity (55.6 \%), Specificity (96.2 \%), PPV (16.4 \%), NPV (99.4\%) from a symptom-related group. Moreover, this result might not represent the incidence of colorectal cancer from all regions in Thailand because most $(81.8 \%)$ of the participants were from the Bangkok metropolitan region and territories. If this finding represented the real incidence of colorectal cancer in our population, or perhaps even in urban and suburban areas, launching a national colorectal cancer screening policy should be considered for specific groups. Other factors that might affect a high yield of colorectal cancer findings include public information that may stimulate awareness and access to reluctant cancer patients.

Problems related to colonoscopy screening include its invasiveness, complications, high financial cost, and need of specialized endoscopists; these reasons were reported as causes of low colorectal screening adherence in well

Table 5 Histopathology characteristics of cases with FIT-positive and FIT-negative results

\begin{tabular}{lll}
\hline Histopathology & FIT $^{\mathrm{a}}$ & \\
\cline { 2 - 3 } & $\begin{array}{l}\text { Positive } \\
N(\%)\end{array}$ & $\begin{array}{l}\text { Negative } \\
\text { N(\%) }\end{array}$ \\
\hline Colorectal cancer & $10(16.4)$ & $8(0.6)$ \\
High risk adenoma & $6(9.8)$ & $87(6.7)$ \\
Low risk adenoma & $3(4.9)$ & $152(11.7)$ \\
Hyperplastic polyp & $8(13.1)$ & $106(8.1)$ \\
Other pathological diagnosis & $1(1.6)$ & $17(1.3)$ \\
No colorectal tumor & $33(54.1)$ & $933(71.6)$ \\
\hline
\end{tabular}

aFIT not done in 40 cases

bInflammatory polyp, colitis, lipoma 
developed countries [24, 25]. Therefore, other more practical screening methods were utilized instead of colonoscopy. The sensitivity of FIT for cancer detection in our study (55\%) was comparable to Guaiac fecal occult blood test (37-79 \%) but somewhat lower than results of FIT in other studies (79 \%) [26, 27]. In some resourcelimited countries, fecal-based screening may play a major role in decreasing colorectal cancer mortality with high subject acceptance rates $[28,29]$. However, in our study, the sensitivity of FIT of $55.6 \%$ was deemed inadequate to detect colorectal cancer cases and 8/18 cancer cases had negative FITs.

There are no recommendations for any other surveillance procedure after screening colonoscopy, but endoscopic management after colonoscopic and pathologic findings have been suggested [30-34]. However, in this study, cases of colorectal cancer were found before the recommended period of surveillance colonoscopy, which were similar to the findings of other studies [5, 24, 35-39]. Moreover, some cases also suffered from unrelated types of cancer. Thus, some individual risk criteria such as smoking, a family history of biliary tract cancer which are common in Thailand should be concerned for improvement of screening benefits in specific groups of patients $[40,41]$. Quality indices [42, 43], technology of colonoscopy [44] and other predictors [45-48] should be included for detection of these interval cancers. Particularly, with the aging population in Thailand, proper screening and surveillance programsneed to be further evaluated [3].

The mortality caused by colorectal cancer in our study after monitoring for 5 years was only two cases from colorectal cancer. Another case died from unrelated hepatobiliary cancer. So the 5-yearsurvival rate after screening colonoscopy and standard treatment of detected colorectal cancer cases in this study, even including five cases $(27.8 \%)$ with stage IIA and IIIB, was excellent at $88.9 \%$. This survival rate was comparable to survival of stage I colorectal cancer (87-92\%) after standard staging and treatment [49].

\section{Conclusions}

In our study population aged 50-65 years old, $30 \%$ of colonoscopically screened cases had abnormal colonic lesions that needed further pathological diagnosis. The colorectal cancer detection rate was $1.3 \%$ and the overall prevalence of advanced colorectal neoplasia was $3 \%$ by screening colonoscopy. Tissue abnormalities were found more in the distal part than the proximal part of the large intestine. The overall survival of colorectal cancer patients diagnosed by colonoscopic screening was $83 \%$. FIT was inadequate to detect advanced colorectal neoplasia and missed almost half of the colorectal cases. We suggest that screening colonoscopy should be implemented as part of the National Colorectal Cancer Screening Program in Thailand.

\section{Acknowledgements}

We appreciated all volunteer participants and Chulabhorn Hospital staff, particularly the Colorectal Cancer Care Team, the Nursing Division and the Data Management Unit, who generously spared their time for the accomplishment and fulfillment of this project.

\section{Funding}

This study was funded by Chulabhorn Hospital Research Grant.

\section{Availability of data and materials}

We do not wish to share all the data at the present time as the project is still ongoing. The full data set will be available by 2019 when the whole project is completed. Researchers wishing to access the data for this study should contact the corresponding author.

\section{Authors' contributions}

BS performed colonoscopy, data collection and manuscript drafting. CM was responsible for the initiation and execution of the entire project. ND, BM and TS performed colonoscopy. TSr and NT reviewed and reported pathological results. WC and WW were responsible for anesthesia of the participants. PS, $J J$ and JP helped coordinating the appointment and follow-ups of the participants and patients. GS was responsible for FIT analysis. KW and KS performed data collection, data management and statistical analysis. CA reviewed the study design, monitored the project, and critically revised the final manuscript. All authors approved to the final manuscript.

\section{Competing interests}

The authors declare that they have no competing interests.

\section{Consent for publication}

Not applicable.

\section{Ethics approval and consent to participate}

This research had been approved by the Human Research Ethical Committee of Chulabhorn Research Institute (certificate no. 05/2556).

\section{Author details}

${ }^{1}$ Chulabhorn Hospital, Bangkok, Thailand. ${ }^{2}$ Chulabhorn Research Institute, Bangkok, Thailand. ${ }^{3}$ Faculty of Medicine Siriraj Hospital, Mahidol University, Bangkok, Thailand.

Received: 1 November 2015 Accepted: 18 August 2016

Published online: 23 August 2016

\section{References}

1. Ferlay J, Shin HR, Bray F, Forman D, Mathers C, Parkin DM. Estimates of worldwide burden of cancer in 2008: GLOBOCAN 2008. Int J Cancer. 2010;127(12):2893-917

2. Hospital based cancer registry National Cancer Institute of Thailand. 2002-2011. http://www.nci.go.th/en/cancer_record/cancer_rec1.html. Accessed 20 July 2012.

3. Zauber AG, Winawer SJ, O'Brien MJ, Lansdorp-Vogelaar I, van Ballegooijen M, Hankey BF, et al. Colonoscopic polypectomy and long-term prevention of colorectal-cancer deaths. N Engl J Med. 2012;366(8):687-96.

4. Winawer SJ. The history of colorectal cancer screening: a personal perspective. Dig Dis Sci. 2015;60(3):596-608.

5. Friedrich K, Gruter L, Gotthardt D, Eisenbach C, Stremmel W, Scholl SG, et al. Survival in patients with colorectal cancer diagnosed by screening colonoscopy. Gastrointest Endosc. 2015;82(1):133-7.

6. Winawer SJ, Fletcher RH, Miller L, Godlee F, Stolar MH, Mulrow CD, et al. Colorectal cancer screening: clinical guidelines and rationale. Gastroenterology. 1997;112(2):594-642.

7. Khuhaprema T, Sangrajrang S, Lalitwongsa S, Chokvanitphong V, Raunroadroong T, Ratanachu-ek T, et al. Organised colorectal cancer screening in Lampang Province, Thailand: preliminary results from a pilot implementation programme. BMJ Open. 2014;4(1):1-11.

8. Aniwan S, Rerknimitr R, Kongkam P, Wisedopas N, Ponuthai Y, Chaithongrat $S$, et al. A combination of clinical risk stratification and fecal immunochemical test results to prioritize colonoscopy screening in asymptomatic participants. Gastrointest Endosc. 2015;81(3):719-27. 
9. Lohsiriwat V. Accuracy of self-checked fecal occult blood testing for colorectal cancer in Thai patients. Asian Pac J Cancer Prev. 2014;15(18):7981-4.

10. Sobin LH, Wittekind C, M. G. TNM classification of malignant tumours (UICC S.). 7th ed. New York: Wiley-Blackwell; 2009. p. 73-7.

11. Network NCC. NCCN Guidelines, Colorectal Cancer, Version I 2010. 2010.

12. Simon JB. Occult blood screening for colorectal carcinoma: a critical review. Gastroenterology. 1985;88(3):820-37.

13. Blebea J, McPherson RA. False-positive guaiac testing with iodine. Arch Pathol Lab Med. 1985;109(5):437-40.

14. Sung JJ, Lau JY, Young GP, Sano Y, Chiu HM, Byeon JS, et al. Asia Pacific consensus recommendations for colorectal cancer screening. Gut. 2008; $57(8): 1166-76$

15. Bae T, Ha Y, Kim C, Lee J, Ha K, Shin S, et al. Distribution of the colonoscopic adenoma detection rate according to age: is recommending colonoscopy screening for koreans over the age of 50 safe? Ann Coloproctol. 2015;31(2):46-51.

16. Rerknimitr R, Ratanapanich W, Kongkam P, Kullavanijaya P. Differences in characteristics of colorectal neoplasm between young and elderly Thais. World J Gastroenterol. 2006;12(47):7684-9.

17. Aswakul P, Prachayakul V, Lohsiriwat V, Bunyaarunnate T, Kachintorn U. Screening colonoscopy from a large single center of Thailand - something needs to be changed? Asian Pac J Cancer Prev. 2012;13(4):1361-4.

18. Wisedopas N, Thirabanjasak D, Taweevisit M. A retrospective study of colonic polyps in King Chulalongkorn Memorial Hospital. J Med Assoc Thai. 2005;88 Suppl 4:S36-41.

19. Arayasakulwong N, Rojborwonwitaya J, Onnom K. Prevalence of colorectal adenomatous polyps in patients undergoing colonosopic examination at rajavithi hospital. Thai J Gastroenterol. 2009;10(1):9-15.

20. Srichan P, Wasutit $Y$, Suwanthanma W, Euanorasetr C, Sornmayura P, Puanfoong $\mathrm{O}$, et al. Characteristic of mixed hyperplastic-adenomatous polyps at ramathibodi hospital. Thai I Surg. 2009;30:17-21.

21. Leggett BA, Devereaux B, Biden K, Searle J, Young J, Jass J. Hyperplastic polyposis: association with colorectal cancer. Am J Surg Pathol. 2001;25(2):177-84.

22. Hyman $\mathrm{NH}$, Anderson $\mathrm{P}$, Blasyk $\mathrm{H}$. Hyperplastic polyposis and the risk of colorectal cancer. Dis Colon Rectum. 2004;47(12):2101-4.

23. SEER Cancer Statistics Review, National Cancer Institute. 1975-2010. http://seer.cancer.gov/archive/csr/1975_2010/. Accessed 20 July 2012.

24. Young PE, Womeldorph CM. Colonoscopy for colorectal cancer screening. J Cancer. 2013;4(3):217-26.

25. Paskett ED, Khuri FR. Can we achieve an $80 \%$ screening rate for colorectal cancer by 2018 in the United States? Cancer. 2015.

26. Allison JE, Tekawa IS, Ransom $\sqcup$, Adrain AL. A comparison of fecal occultblood tests for colorectal-cancer screening. N Engl J Med. 1996;334(3):155-9.

27. Lee JK, Liles EG, Bent S, Levin TR, Corley DA. Accuracy of fecal immunochemical tests for colorectal cancer: systematic review and meta-analysis. Ann Intern Med. 2014;160(3):171.

28. Giorgi Rossi P, Vicentini M, Sacchettini C, Di Felice E, Caroli S, Ferrari F, et al. Impact of screening program on incidence of colorectal cancer: a cohort study in Italy. Am J Gastroenterol. 2015;110(9):1359-66.

29. Saengow U, Chongsuwiwatvong V, Geater A, Birch S. Preferences and acceptance of colorectal cancer screening in Thailand. Asian Pac J Cancer Prev. 2015;16(6):2269-76.

30. Levin B, Lieberman DA, McFarland B, Andrews KS, Brooks D, Bond J, et al. Screening and surveillance for the early detection of colorectal cancer and adenomatous polyps, 2008: a joint guideline from the American Cancer Society, the US Multi-Society Task Force on Colorectal Cancer, and the American College of Radiology. Gastroenterology. 2008;134(5):1570-95.

31. Cairns SR, Scholefield JH, Steele RJ, Dunlop MG, Thomas HJ, Evans GD, et al. Guidelines for colorectal cancer screening and surveillance in moderate and high risk groups (update from 2002). Gut. 2010;59(5):666-89.

32. Lieberman DA, Rex DK, Winawer SJ, Giardiello FM, Johnson DA, Levin TR. Guidelines for colonoscopy surveillance after screening and polypectomy: a consensus update by the US Multi-Society Task Force on colorectal cancer. Gastroenterology. 2012;143(3):844-57.

33. Fairley K, Li J, Komar M, Steigerwalt N, Erlich P. Predicting the risk of recurrent adenoma and incident colorectal cancer based on findings of the baseline colonoscopy. Clin Transl Gastroenterol. 2014;5:e64.
34. Provenzale D, Jasperson K, Ahnen DJ, Aslanian H, Bray T, Cannon JA, et al. Colorectal cancer screening, version 1.2015. J Natl Compr Canc Netw. 2015;13(8):959-68.

35. Imperiale TF, Glowinski EA, Lin-Cooper C, Larkin GN, Rogge JD, Ransohoff DF. Five-year risk of colorectal neoplasia after negative screening colonoscopy. N Engl J Med. 2008;359(12):1218-24.

36. Leung WK, Lau JY, Suen BY, Wong GL, Chow DK, Lai LH, et al. Repeatscreening colonoscopy 5 years after normal baseline-screening colonoscopy in average-risk Chinese: a prospective study. Am J Gastroenterol. 2009;104(8):2028-34.

37. Brenner $\mathrm{H}$, Chang-Claude J, Seiler CM, Hoffmeister M. Long-term risk of colorectal cancer after negative colonoscopy. J Clin Oncol. 2011:29(28):3761-7.

38. Chung SJ, Kim YS, Yang SY, Song JH, Kim D, Park MJ, et al. Five-year risk for advanced colorectal neoplasia after initial colonoscopy according to the baseline risk stratification: a prospective study in 2452 asymptomatic Koreans. Gut. 2011;60(11):1537-43.

39. Shergill AK, Conners EE, McQuaid KR, Epstein S, Ryan JC, Shah JN, et al. Protective association of colonoscopy against proximal and distal colon cancer and patterns in interval cancer. Gastrointest Endosc. 2015;82(3):529-37. e1.

40. Brenner $\mathrm{H}$, Chang-Claude J, Seiler CM, Hoffmeister M. Interval cancers after negative colonoscopy: population-based case-control study. Gut. 2012;61(11):1576-82.

41. Itatsu K, Yokoyama Y, Ebata T, Igami T, Sugawara G, Uehara K, et al. The value of preoperative screening colonoscopies in patients with biliary tract cancer. J Gastroenterol. 2016;51(2):138-43.

42. Robertson DJ, Kaminski MF, Bretthauer M. Effectiveness, training and quality assurance of colonoscopy screening for colorectal cancer. Gut. 2015;64(6):982-90

43. Ross WA, Thirumurthi S, Lynch PM, Rashid A, Pande M, Shafi MA, et al. Detection rates of premalignant polyps during screening colonoscopy: time to revise quality standards? Gastrointest Endosc. 2015;81(3):567-74.

44. Hassan C, Gralnek IM. Cost-effectiveness of "full spectrum endoscopy" colonoscopy for colorectal cancer screening. Dig Liver Dis. 2015:47(5):390-4.

45. Singh H, Turner D, Xue L, Targownik LE, Bernstein CN. Risk of developing colorectal cancer following a negative colonoscopy examination: evidence for a 10-year interval between colonoscopies. J Am Med Assoc. 2006; 295(20):2366-73.

46. Bressler B, Paszat LF, Chen Z, Rothwell DM, Vinden C, Rabeneck L. Rates of new or missed colorectal cancers after colonoscopy and their risk factors: a population-based analysis. Gastroenterology. 2007;132(1):96-102.

47. Lakoff J, Paszat LF, Saskin R, Rabeneck L. Risk of developing proximal versus distal colorectal cancer after a negative colonoscopy: a population-based study. Clin Gastroenterol Hepatol. 2008;6(10):1117-21. quiz 064.

48. Singh $\mathrm{H}$, Nugent Z, Demers AA, Bernstein CN. Rate and predictors of early/ missed colorectal cancers after colonoscopy in Manitoba: a populationbased study. Am J Gastroenterol. 2010;105(12):2588-96.

49. Colorectal Cancer Facts \& Figures 2014-2016. American Cancer Society, Atlanta. 2014. http://www.cancer.org/acs/groups/content/documents/ document/acspc-042280.pdf. Accessed 8 Oct 2015.

\section{Submit your next manuscript to BioMed Central and we will help you at every step:}

- We accept pre-submission inquiries

- Our selector tool helps you to find the most relevant journal

- We provide round the clock customer support

- Convenient online submission

- Thorough peer review

- Inclusion in PubMed and all major indexing services

- Maximum visibility for your research

Submit your manuscript at www.biomedcentral.com/submit 